\title{
Creating Public Service Excellence Applying Learning Organisation Methods: The Role of Strategic Leadership
}

\author{
Nico Schutte \\ Department of Public Administration, North-West University, \\ Mafikeng Campus, South Africa \\ nico.schutte@nwu.ac.za \\ Nicolene Barkhuizen \\ Department of Industrial Psychology, North-West University, \\ Mafikeng Campus, South Africa \\ nicolene.barkhuizen@nwu.ac.za
}

Doi:10.5901/mjss.2014.v5n4p159

\begin{abstract}
Effectiveness and efficiency in South Africa is high on government's agenda. The main objective of this research was to determine the role of a strategic leader in creating a learning organisation for public sector effectiveness. The sample was based on interviews and focus group discussions with strategic leaders that represent five major central government institutions $(N=168)$. The results showed that leaders need to display a high level of consciousness of their effect on the organisation and employees. Leaders also provide the necessary guidance and motivation towards and effective and efficient learning organisation. Finally the results showed that leaders need to be able to adapt to rapid changing environments to apply organisational learning effectively in public service institution. This paper concludes with an integrated framework relating Strategic Leadership, Organisational Learning and Public Sector Effectiveness.
\end{abstract}

Keywords: Strategic Leadership, Learning organisation, Public Service, Organisational Effectiveness

\section{Introduction}

Government plays an important role in the wealth creation of any nation. The public service in particular is a transparent system, embedded in a thriving environment that not only sets the pace, but also outlines the actions to be taken by institutions within this service. In any society the affairs of the people must be regulated in the interest of all, with a view to promote the general welfare of society (Paradza, Mokwena \& Richards, 2010; Roux, Brynard, Botes \& Fourie, 1997, p. 207).

Government leaders thus have a major responsibility of bringing together the resources to produce products and deliver services. Legislation dictates that leaders should amongst others develop strategic management plans in keeping with the medium-term expenditure framework, organisational structures that comply with the strategic management plans and strategies to improve service delivery (Public Service Act, 1994, SA, 1994 and Public Service Amendment Act 30 of 2007). This implies that leaders should have the mindset to create an organisational culture that unleashes passion, commitment, and performance of people which in turn contributes to the organisation achieving its mission, vision, and business goals (McArdle \& Ramerman, 2008). In a similar vein Munro's (2005, p. 53) view is that leadership is "the capacity to influence others through inspiration, motivated by a passion, generated by a vision, produced by a conviction, ignited by a purpose". The right leadership mindset is thus critical to an organisation's competitive advantage, with benefits both the individual and the organisation (Morton, 2008).

Yet our understanding of how leaders' mindset influences service excellence and the outcomes thereof is limited. The South African government is facing serious challenges relating to service delivery. Research continues to point out problems in the public service that lead to the failure to deliver services to the local population (see Mabille \& Barkhuizen, 2013; Mtila, Barkhuizen \& Mokgele, 2013; Paradza et al., 2010).

One possible explanation can be a result of the fact that public service leaders are slow to respond and adapt to environmental changes (Mabille \& Barkhuizen, 2013). Although change is important for organisational survival, it causes 
destabilisation of the organisation and is therefore important to make change a management issue (Coetzee \& Stanz, 2007). Strategic leaders are the ones who decide on when to change, how to implement the change and the desired outcomes they want from the change (Schutte, 2010). In making those decisions, it is imperative that leaders are competent, in other words has the necessary knowledge, skills and attitude about the stages people will go through psychologically when they deal with change. This will enable them to assess whether they are managing transition successfully or if there is a need to address additional problems (Schutte, 2010).

Many organizational leaders are therefore seeking to adopt the latest technique or tool in order to keep up with the unrelenting pace of change and extreme competitive pressure. To this end the concept of a learning organisation can be a useful mechanism in assisting public sector leaders to adapt more effectively to change and at the same time improve service excellence. For purposes of this research we define the learning organisation as "organisations that are designed to increase competitiveness through generative learning that is forward looking and reduces the major shock of change through close relationships with customers and other key constituencies that allow for mutual adjustment and through the ability to quickly configure and reallocate resources based on environmental change (Kontoghiorghes, Awbrey \& Feurig cited in Naves, 2011).

Organisational learning is thus reflected by changes in institutional actions and performance outcomes as well as shifts in values, assumptions and approaches to inquiry" (Boyce, 2003, p. 124). Therefore, organisational learning took place not only when changes in how the organisation conducted its business occurred, but also when there were changes in why the organisation (public service) conducted its business as it did. Changing the understanding of why an organisation (public service) conducted business as it did involved collective learning that took place within the culture of the organisation, or inquiry into the meanings, assumptions, and values that are embedded within the organisation (Awbrey, 2005, Boyce, 2003). Accordingly, for public service institutions, organisational culture represented how strategic leaders viewed the relationship between their practice and performance (competence) as well as the learning of members. Strategic leaders within a public institution have to challenge their values, beliefs, and assumptions about this relationship before they could begin to learn as an organisation.

The main objective of this paper was to explore whether a learning organisation approach can enhance public service effectiveness and efficiency. More specifically this research sought to determine the role of a strategic leader in creating a learning organisation in the public sector. The learning organisation methodology is created on specific characteristics and principles that affect and impact on the learning culture of the organisation. A learning organisation is a form of organisation that enables learning of its members in such a way that creates positively valued outcomes, such as innovation, efficiency, better alignment with the environment and competitive advantage (Armstrong \& Foley 2003, p. 74). Reynolds and Ablett (in Steward 2003, p. 141) consider a learning organisation to be one where learning takes place that changes behaviour in the organisation itself and where organisational learning has reached the stage of successful adaptation to change and uncertainty through development of new solutions. A learning organisation is one in which every interaction is viewed as an opportunity to increase understanding, widen or sharpen our thinking abilities and anticipate future changes, it is commonly viewed as the foundation for innovation, efficiency, and competitiveness in the world economy of today and tomorrow (Yong Kim 2006, p.82).

These embedded principles have to be in place before an organisation could refer to itself as a learning organisation. Instituting these embedded principals is an enormous challenge for the South African Public Service. Although there is growing understanding of the characteristics of learning organizations, the applications thereof in the public sector remain scant. We believe that by exploring and understanding key leadership principles in creating learning organisations will help organisations to foresee what working environments and jobs accept organisational change and will alleviate or perhaps eliminate symptoms of change (Van Emmerik, Bakker \& Euwema, 2009).

In what follows next the research propositions are presented followed by the results and discussion of the results of the study. This paper concludes with recommendations for the application of a learning organisation in the public service.

\section{Research Design}

This research followed a qualitative approach. Qualitative research was deemed the most appropriate method to explore the extent to which leaders can enhance service excellence in the public service by applying the learning organisation approach. The sample was based on interviews and focus group discussions with strategic leaders that represent five major central government institutions ( $N=168)$.

Grounded theory was used to analyse the data. Grounded theory provides a methodological way forward to 
addressing our understanding of how to make sense of and explain the manifestation of contextualised leadership. Further, it may allow us to suggest causal explanations of the leadership manifestation in particular contexts such as the public service and across contexts through levels of abstraction related to levels of analysis. Grounded theory seeks to understand people's words and actions in contexts and develop explanations through interpretation (Corbin \& Strauss, 2008). In addition, Parry (1998, p.85) asserts that leadership is a social influence process and that mainstream research methodologies have been partially unsuccessful in theorising about the nature of these processes. Therefore, grounded theory, if rigorously applied, can help to overcome these deficiencies. As a methodology grounded theory is particularly suitable for meeting the interpretive requirements of generating a "sensitive understanding" (Brooks, 1998, p. 5) of the processes by which people make sense of their organisational lives.

The grounded theory methodology involves integration of data collection and data analysis to achieve 'constant comparison' (Creswell, 1998). The concurrent procedure included jotting down ideas that came to mind, making a list of key topics and passages, coding, turning topics into categories, and assembling the material belonging to each category in one place to perform the preliminary analysis. This grounded theory coding process allowed the researchers to both construct codes and generate a description of the themes for analysis. The agreed upon themes, coupled with meaning derived from information gleaned from the literature, will be described in detail in the following section.

\section{Findings}

Three main themes emerged from the data analyses: Strategic leader consciousness (1), Leadership roles and outcomes (2) and Leadership adaptation to change (3). Several sub-themes also emerged from the main themes. The findings relating to each main theme are discussed in the ensuing session and substantiated by direct quotes of the participants.

\subsection{Theme 1: Strategic Leadership Consciousness}

From the interviews and focus group sessions it was evident that leaders need to be display a high level of consciousness of their effect on the organisation as well as organisation members. As mentioned by one participant:

"By focusing on the public service as an entity, we as strategic leaders are constantly faced with asking the question who are we as a public service, determining on what is it that we as a public service do and envisioning where do it want to go. In doing so requires us as strategic leaders to pronounce the public service's values, beliefs, and uniqueness, as well as to create a balance among the public service's core competencies to utilise the present while at the same time embracing organisational learning to discover both knowable and unknown public service expectations" Understanding your role as strategic leaders and the public service's local context and members expectations. Understanding local community needs and dealing with issues of organisational culture are also important issues for strategic leaders."

Another participant added: "I found out that it is very important to understand organisational culture, the environment, members' way of life, and their thinking. That is very, very important to develop this understanding for strategic leaders....because what goes in one department as a form of leadership strategy may be difficult in another department because of the culture....so one really had to understand where the people are coming from. Later s/he continued, "... we found that what we sat down to do in the offices was not realistic when we got out in the field... what we thought they needed were not the things they needed".

In addition, a third participant also conveyed the importance of communication skills for strategic leaders when he said that ..."communication is the most important skill in an organisation, because my own experience was, awakening, that, particularly when you are talking in a diverse setting such as the public service and people coming from diverse backgrounds, it is not easy to communicate what you want to communicate to members and peers. Because of many typical issues with language, like particularly when it is oral one-to-one communication, your meaning, your phrasing, all these are so different, so to convey so that the other person understand and to make him understand what you really want or need.....Not only at the level of language but even in terms of body language, maybe sometimes our mutual customs are, they have meaning in a particular cultural setting, but that could be really different in a different cultural setting. So by communication I would mean understanding the other person and making oneself understand the other person in the right way.

As a relatively new public service, the South African public service strategic leaders has to play an important role 
in the development of the public service 's procedural and trans-active memories as well as the facilitation of creative problem solving. Furthermore they also need to grant access to and encouraging the sharing of knowledge and information: Knowledge about the public service history, knowledge about issues confronting the public service in real time, and knowledge about possible futures.

\subsection{Theme 2: Leadership roles and outcomes}

The findings showed that strategic leaders are key role players in leading the organisation and as such needs to provide the necessary guidance and motivation towards and effective and efficient organisation. The participants confirmed that strategic leadership can be very challenging but rewarding work. None of the participants had any difficulty identifying that strategic leadership is very important for the public service in becoming effective and efficient. They were also clear that within a changing organisation strategic leader is a pivotal role player. Several of the participants related touching stories of intense personal challenges they had faced as strategic leaders trying to guide and motivate their members in a changing environment. Every $r$ participants who recounted experiences that had been especially challenging also stated how much they had learned from it, and how enriching the experience had been.

Related to the idea of strategic leaders as key role players, other compelling statements referred to the challenge of controlling one's own desires to provide answers and the need to be seen as the expert. This was especially evident in departments where so there is a lack of infrastructure and capacity. They indicated that it was hard to give up the assumption that you knew how to do things better or had the answers. A participant spoke of how one "had to be willing to not have all the answers," to "acquire new knowledge from the people," that it required "attentive listening," and that "managing your own expectations, controlling your own anxiety was a key challenge" in guiding members towards organisational objectives. Furthermore, participants also alluded to the idea that as strategic leaders thy need to set an example as a motivation factor for members. One participant said: "We are having a lot of corruption problems, so I think nowadays that people wants somebody who they trust and respect, one who is honest; I think this is very important. We need those qualities now. Our country needs leaders like this."

In addition, participants also discussed political, economic, and societal contexts that constitute the fabric of the public service. They spoke of the South African context in which the political stability could not be taken for granted or where issues of corruption and nepotism took precedence over public service accountability. Participants mentioned situations where the country's infrastructure and support systems varied from being in place, though ineffective, and where societal feelings towards public service deliver are diminishing. The comments referred both to the lack of systems they saw as being favourable as well as to the presence of political or economic factors they saw as hindrances to effective strategic leadership.

Subsequently, public service strategic leaders need to take cognizance of the fact that the public service is a social learning system. "In a social learning system, competence is historically and socially defined. According to Wenger (2003, p. 77) knowing, therefore, is a matter of displaying competencies defined in social communities . . . "socially defined competence is always in interplay with our experience. It is in this interplay that learning takes place." These competencies allow the public service strategic leaders as active performers to modify their ways of thinking or acting when dealing with changing environments.

Furthermore, Hargreaves and Fink (2003, p. 696) made a connection between leadership and collective responsibility by describing it as a "network of relationships of people, structures, and cultures [and] leadership is... dependent on interrelationships and connections." Departments are an integrated and interrelated system and not independent departments. They are all autonomist in their own right for the effectiveness and efficiency of each department within the public service. Moreover, public service strategic leaders is neutral in line with their satisfaction rating, thus taking a collective responsibility in that they do not view the public service possessing the necessary strategic leadership competencies in order to be effective as a collective unit (Schutte, 2010).

Subsequently, there is an expectation of public service leaders to acquire the capacity, reflective practice that leads consistently to innovation. Lambert $(2003$, p. 7) defined reflective practice as "thinking about your own practice and enabling others to think about theirs". Reflection is part of the cycle of inquiry and is an integral part of public service improvement, since understanding what was is central to understanding what is and what can be for a public service institution. Supporting reflection that leads to learning, Morgan (1997, p. 92) asserted that to learn and change, organisational members "must be skilled in understanding the assumptions, frameworks, and norms guiding current activity and be able to challenge and change them when necessary." Boyce (2003, p. 124) summarised that "successful institutional change is indicated by changes in institutional actions and performance outcomes, as well as shifts in values, 
assumptions, and approaches to inquiry". Reflective practice leads to learning and learning leads to innovation that supports sustaining public service improvement.

\subsection{Theme 3: Leadership adaptation to change}

Data regarding skills that strategic leaders need to keep track of new trends was gathered from the question that asked specifically about what competencies are deemed necessary to be effective as a strategic leader as well as comments made regarding how strategic leaders could apply these competencies to transform the public service into a learning organisation. The findings clearly showed that the public service strategic leaders need to keep track of new trends due to a rapid changing environment they can use and apply organisational learning effectively in their positions.

One participant for example indicated that: "the public service as a learning organisation must strive to anticipate change in the environment in which it operates. The community its serves expect the public service to become more accountable for service delivery indebted to its trustworthiness in responding to those anticipated changes" Another participant added: "The first thing is to listen. You must develop the ability to listen, and to see what we cannot see if we can, and to hear what we don't hear, and to understand what is difficult to understand." And "The first thing I would say is that a very important factor is one's level of competence.... and the second factor is, over time, whether you are a person that can be trusted." "...s/he will be visionary, tactful, open, and sincere..." "Drive, because if you don't have the drive you will not have the other things...and then come the other things, flexibility, openness, trustworthiness..." Another participant said, "Being a leader in a local context, you have to be good at politics. You don't need to have many skills, or years of study to be a leader in the local context. But being a good leader in the international context, that's completely different. You have to prove that you are good; we need to have more competence and social intelligence."

Based on the above findings one can conclude that the learning-organisation paradigm encourages organisations such as the public service to use information and technology to improve understanding of changes in the environment, and institute new practices and procedures to meet emerging environmental conditions (Schutte, 2010). Yet, given these three limitations - asymmetrical decision parameters, ill-structured problem environments, and immature cognitive capabilities - the public service may not offer the signalling and adaptability benefits assumed and required by the learning organisation. These three conditions not only may undermine organisational adaptability, but when decision making is contingent on the available Information and technology, the public service may actually institutionalise organisational rigidity. Perhaps the greatest concern is that, under the influence of these three conditions, the public service may promote rigidity, leaving the organisation less, rather than more, able to respond to environmental turbulence. Moreover, Liker (2004, p. 251) is also of the opinion that if the public service wants to sustain such organisational behaviour an indispensable element is required: the ability to learn and to learn fast which is accredited to being a learning organisation. Therefore, it is imperative for strategic leaders within the public service to mobilise its employees at all levels around the strategic intent, effective and efficiently distribute resources across organisational boundaries, realise and using opportunities, developing and redeploying core competencies, consistently satisfying customers.

In addition, there is an expectation of public service leaders to acquire the capacity, reflective practice that leads consistently to innovation. Lambert (2003, p. 7) defined reflective practice as "thinking about your own practice and enabling others to think about theirs". Reflection is part of the cycle of inquiry and is an integral part of public service improvement, since understanding what was is central to understanding what is and what can be for a public service institution. Supporting reflection that leads to learning, Morgan (1997, p. 92) asserted that to learn and change, organisational members "must be skilled in understanding the assumptions, frameworks, and norms guiding current activity and be able to challenge and change them when necessary". Boyce (2003, p. 124) summarised that "successful institutional change is indicated by changes in institutional actions and performance outcomes, as well as shifts in values, assumptions, and approaches to inquiry". Reflective practice leads to learning and learning leads to innovation that supports sustaining public service improvement.

\section{Discussion}

The above findings lead to the development of an integrated framework relating strategic leadership the learning organization and public service outcomes (see Figure 1 below). We adopt a multi-level perspective including three types of environments namely: Macro, Meso and Micro. It is important to note that these three environments are in continuous interaction with each other and also influence each other. We believe that leaders have to take cognisance of all three 
environments in order to implement learning organisation principles and achieve subsequent organisational effectiveness.

The macro-environment environment represents the Global and South African Environment. Organisations are continuously changing as a result of emerging economic environmental changes, uncertainty in the corporate world, new technology and new emerging world markets. Leaders need to be knowledgeable about these changes and the impact thereof on their organisation. The findings highlighted that leaders need to be able to anticipate changing client expectation and adapt their organisation to meet growing customer need. In addition leaders also need to align the organisation current strengths and both known and unknown public service expectations.

The Meso-environment includes the South African Government. The Government passes legislation and policies that regulate the business practices of the public service. As mentioned earlier strategic leaders need to develop strategic management plans in keeping with the medium-term expenditure framework, organisational structures that comply with the strategic management plans and strategies to improve service delivery.

Finally the Micro-environment consists of the organisation itself. Leaders need to have the vision, skills and ability to create a learning culture in the midst of organisational and broader macro and micro challenges to achieve effectiveness, efficiency and sustainability.

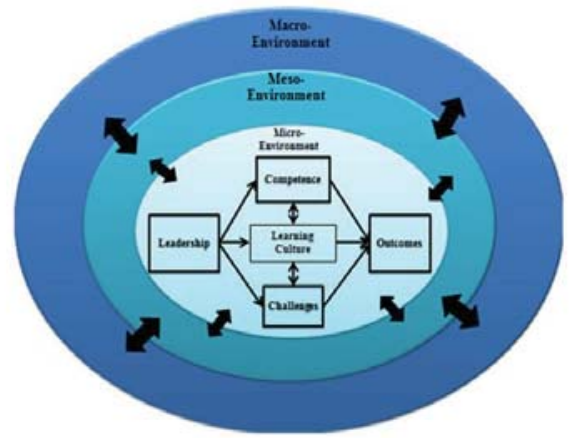

Figure 1: Integrated Framework relating Strategic Leadership, Organisational Learning and Public Service Excellence

\section{Conclusions and Recommendations}

The public service as a learning organisation needs to facilitate organisational sustainability and effective and efficient service delivery as it promotes an organisation's ability to be adaptable to continuous changes in its environment and therefore continue to transform itself. Strategic leaders within the public service and their preparedness to learn and learn fast are the key to public service sustainability. To be a learning organisation, it is necessary to have competent staff and very careful succession systems to protect the organisational knowledge base. As a learning organisation the public service need to proactively create an environment and mechanisms that allow it to think and act systematically to achieve goals of sustainable growth and effective and efficient service delivery. Strategic leaders within the public service thus carefully need to plan the implementation of a learning organisation taking cognizance of the fact that it is a long term process that seeks unconditional commitment from all stakeholders.

Therefore, for the public service to become an learning organisation it needs to understand that a prerequisite for the public service is that it needs systems, mechanisms and processes in place which, facilitates learning of its members to create expected organisational outcomes, learning that takes place changes behaviours and every single interaction is viewed as an opportunity to increase understanding sharpen thinking abilities and anticipate future changes. Subsequently, the public service as organisation will develop new conducts and practices (culture), improved performance of the public service as organisational system and reaches the stage of effective adaptation to change and uncertainty through the development of precise solutions which results in constructively valued outcome.

Thus, as a newly developed public service South African public service strategic leadership is concerned with linking the past, the present, and the future of the public service to ensure stability in the face of change and development towards sustainable growth. In doing so, public service strategic leaders can influence the organisation directly through their inter and intra-connections and competence, or indirectly by embracing the creation, orchestrating, knowledge corridors and/or serving as the heart of intra- and extra-organisational networks through which the public 
service learn and transfer knowledge.

In addition, the public service officials-human resources are the most important assets of the public service as an organisation. Hence, in the current knowledge economy the focus is more on people as talent that will give the public service its thrust towards service excellence. Moreover, as a transforming organisation the public service must position itself to have the ability to learn as organisations and the capacity to respond quickly to the continuously changing demands of their respective communities. Subsequently the public service as a learning organisations are also about how members within the organisations interact with one another and with the organisation as they address the public service's challenges.

\section{References}

Awbrey, S.M. (2005). General Education reform as organisational change: Integrating cultural and structural change. The Journal of General Education, 55, 1-22.

Armstrong, A., \& Foley, P. (2003). Foundations for a learning organization: organization learning mechanisms. Learning Organization, $10,74-82$

Boyce, M. E. (2003). Organizational learning is essential to achieving and sustaining change in higher education. Innovative Higher Education, 28, 119-136.

Brooks, I. (1998), Weighing Up Change: A Grounded Theory Explaining the Response of Middle Managers to Organisational Change. $\mathrm{PhD}$ thesis. Department of Management, University of Canterbury, New Zealand.

Coetzee, C.J.H., \& Stanz, K.J. (2007). "Barriers-to-Change" in a Governmental service delivery type of organisation. South African Journal of Human Resource Management, 33(2), 76-82.

Corbin, J. \& Strauss, A. (2008). Basics of Qualitative Research: Techniques and Procedures for Developing Grounded Theory (3rd ed.). Sage Publications Inc.

Creswell, J. W. (1998). Qualitative inquiry and research design: Choosing among five designs. Thousand Oaks, CA: Sage.

Hargreaves, A. \& Fink, D. (2003). Sustaining leadership. Phi Delta Kappan, 84(9), 693-700

Lambert, L. (2003). Leadership capacity for lasting school improvement. Alexandria,

VA: Association for Supervision and Curriculum Development.

Liker, J. K. 2004. The Toyota way: 14 management Principles from the greatest manufacturer. New York: Mc Graw-Hill.

Mabille, T., \& Barkhuizen, E.N. (2013). An Analysis of Municipal Financial Management in South Africa. In N. Delener, L. Fuxman, F. Lu, S. Rodrigues \& L. Rivera (Eds.), 15th Annual International Conference on Globalizing Businesses for the Next Century: Visualizing and Developing Contemporary Approaches to Harness Future Opportunities, Global Business and Technology Association, Helsinki, Finland (pp. 564-570), ISBN: 1-932917-08-X. USA, Gbata.

McArdle, S. \& Ramerman, J. (2008). Strategic Talent Management. [Online] Retrieved from: http://www.managesmarter.com/msg /content display/training/e3i826839942e5a637a4e243acf654f6e48

Morgan, G. (1997). Images in organizations (2nd Ed.). Thousand Oaks, London: Sage Publications.

Morton, L. (2004). Talent Management: A Critical Way To Integrate \& Embed Diversity. Retrieved from http://www.workinfo.com /free/Downloads/259.htm

Mtila, J., Barkhuizen, E.N. \& Mokgele, R. (2013). Exploring the Application of Talent Management Practices in a Local Government Institution. In S.M. Lee \& G. Roodt (Eds.), 30th Pan Pacific Conference, Johannesburg, South Africa (pp. 66-68) ISBN: 1-93164927-3. PPBA.

Munro, M. 2005. The Spirit of Leadership. "Cultivating The Attitudes That Influence Human Action". Whitaker House, USA.

Naves, P. (2011). Learning Organisations and Organisation Learning: Two sides of the same coin? http://www.sabpp.co.za/wpcontent/uploads/2012/learning-organisation-final.pdf

Paradza, G., Mokwena, L. \& Richards, R., 2010. Assessing the role of councillors in service delivery at local government level in South Africa, Johannesburg: Centre for Policy Studies.

Parry, K. (1998), Grounded Theory and Social Process: A New Direction for Leadership Research. Leadership Quarterly, vol 9, no 1, pp 85-105

Public Service Act, 1994, SA, 1994 and Public Service Amendment Act 30 of 2007. Government Gazette.

Roux, NL, Brynard, P, Botes, P, \& Fourie, D. (1997). Critical Issues in Public Management in South Africa. Cape Town: Kagiso Tertiary.

Steward, D. 2001. Reinterpreting the learning organisation. The Learning Organisation Journal, 8,141-152.

Van Emmerik, I.J.H., Bakker, A., \& Euwema, M.C. (2009). Explaining employees evaluations of organisational change with the jobdemands resources model. Career Development International, 14(6), 594-613.

Wenger, E. (2003). Communities of practice and social learning systems. In D. Nicolini, S. Gherardi, and D. Yanow (eds.), Knowing in organizations: A practice-based approach (pp. 176-99). New York: M. E. Sharpe, Inc,

Yong Kim, B. (2006). Managing workforce Diversity: Developing a Learning organisation. Journal of Human Resources in Hospitality \& Tourism, 5, 69-90. 